\title{
Impact of Acute and Chronic Co-morbidities on Psychosexual Concerns
}

It is acknowledged that there are a myriad of acute and chronic co-morbidities associated with psychosexual concerns [1]. As radical prostatectomy is one of the most widely accepted treatments for prostate cancer [2], there are "to be expected" side effects of. There are conflicting rates of erectile dysfunction, which may not only be associated with degree of surgery, but also presence of co-morbidities [3]. Vascular, cardiac and diabetic comorbidities have the greatest impact [4, 2]. Age will not improve this function [5]. Additionally, if a patient has poor erections before surgery, this will not improve post-operatively [6].

\section{References}

1. Kendirci M, Bejma J, Hellstrom WJG. Update on erectile dysfunction in prostate cancer patients. Curr Opin Urol. 2006;16:186-95.

2. Teloken PE, Mulhall JP. Erectile function following prostate cancer treatment: factors predicting recovery. Sexual Medicine Reviews. 2013;1:91-103.

3. Sherer BA, Levine LA. Current management of erectile dysfunction in prostate cancer survivors. Curr Opin Urol. 2014;24:401-6.

4. Miner MM. Erectile dysfunction: a harbinger for cardiovascular events and other comorbidities, thereby allowing a 'window of curability'. Int J Clin Pract. 2009;63:1123-6.

5. Albersen M, Orabi H, Lue TF. Evaluation and treatment of erectile dysfunction in the aging male: a mini-review. Gerontology. 2012;58:3-14.

6. Han M, Trock BJ, Partin AW, Humphreys EB, Bivalacqua TJ, Guzzo TJ, Walsh PC. The impact of preoperative erectile dysfunction on survival after radical prostatectomy. BJU Int. 2010;106:1612-7. 